\title{
Effects of ozone pretreatment on drying kinetics and quality of Granny Smith Apple dried in a fluidized bed dryer
}

\author{
Fonteles, T. V. ${ }^{\text {a }}$ Nascimento, R. B. R. ${ }^{\text {a }}$; Rodrigues, S. ${ }^{a^{*}}$; Fernandes, F. A. N. ${ }^{\text {b }}$ \\ ${ }^{a}$ Department of Food Engineering. Federal University of Ceará, Ceará, Brazil \\ ${ }^{\mathrm{b}}$ Department of Chemical Engineering. Federal University of Ceará, Ceará, Brazil \\ *E-mail of the corresponding author: sueli@ufc.com
}

\begin{abstract}
This study aimed to evaluate the effects of ozone pretreatment on drying of green apple carried out in a fluidized bed dryer to determine drying kinetics and identify operating parameters for improved product quality. Results reveal that drying temperature in different levels affected water diffusivity and retention of bioactive compounds. The ozone pretreatment showed unexpected results since the pretreatment reduced the water difusivity and promoted an increase in the enzyme activity. The treatment time strongly afftected the final polyphenoloxidase and peroxidase activities. On the other hand, the ozone treatment resulted in lower color changes compared to non-ozone treated dried apples.
\end{abstract}

Keywords: diffusivity; polyphenoloxidase; enzymatic browning; ozone. 


\section{Introduction}

Foods with high moisture like fruits and vegetables are dried to increase shelf storage and to reduce the storage and transportation costs. However, the drying methods used for food should be not only efficient and economical but also produce high quality, tasty and nutritious products with good uniformity, appearance, and texture. The main challenge in drying food is to maintain the quality of the product ${ }^{1,2}$.

The drying process is related to the simultaneous application of heat and removal of food moisture. The main parameters that control the drying rate of fruits are the air temperature, relative air humidity and air velocity as processing conditions variables. These parameters are chosen based on the nature of the food and the particular design of the dryer ${ }^{3,4}$. Fluidized bed drying is a method for controlled and mild drying of wet solids. A proper bed flow control provides a homogeneous drying, with greater drying efficiency without the application of excessive heat and mass transfer when compared to other conventional drying systems. However, the efficiency of a conventional fluidized bed system is usually low. It is, therefore, desirable to improve the efficiency of the drying process.

Pretreatment with ozone in fruits and vegetables is usually carried out to prolong its shelf life. One of the applications of ozone as a preservative treatment in fresh fruits and vegetables is due to the effective increase of the antioxidant defense system by increasing the activity of superoxidase dismutase (SOD), peroxidase (POD) and catalase (CAT) ${ }^{5}$.

Polyphenoloxidases are enzymes responsible for the enzymatic browning in fruits and vegetables. These enzymes also cause degradation of polyphenols, leading to discoloration and loss of antioxidant activity ${ }^{2}$.

Thus, this study aimed to evaluate the application of ozone pretreatment before drying of green apple carried out in a mini vibrated fluidized bed dryer to determine drying kinetics and identify the main operating parameters for improved product quality.

\section{Materials and Methods}

\subsection{Preliminary drying tests}

The apples (Granny Smith variety) were cut in cubes $(0.5 \mathrm{~cm})$ and dried at 40,45 or $50^{\circ} \mathrm{C}$ in a mini fluidized bed dryer and evaluated in different temperature and air flow parameters (Table 1). The final moisture obtained was $10 \%$ (dry base), and the processing effects on color parameters, phenolic compounds, antioxidant capacity (DPPH) ${ }^{6}$ and the polyphenol oxidase (PPO) and peroxidase (POD) activities ${ }^{2}$ were evaluated. The optimum drying temperature was selected based on the effective water diffusivity of apple cubes calculated using Fick’s law. 
Table 1. Drying parameters

\begin{tabular}{llll}
\hline $\begin{array}{l}\text { Temperature } \\
\left({ }^{\circ} \mathrm{C}\right)\end{array}$ & $\begin{array}{l}\text { Airflow } \\
\left(\mathrm{m}^{3} / \mathrm{min}\right)\end{array}$ & $\begin{array}{l}\text { Final Airflow } \\
\left(\mathrm{m}^{3} / \mathrm{min}\right)\end{array}$ & $\begin{array}{l}\text { Drying time } \\
(\mathrm{h})\end{array}$ \\
\hline 40 & 75 & 40 & 2 \\
45 & 75 & 40 & 2 \\
50 & 75 & 40 & 2 \\
\hline
\end{tabular}

\subsection{Ozone pretreatment}

To evaluate the blanching effects of ozone pretreatment on dried apples, the cubes were inserted into a glass column reactor with a sintered glass porous plate $(4.5 \mathrm{~cm}$ in diameter and $30 \mathrm{~cm}$ hight), coupled to a Model O \& L1.5 Portable Ozone Generator, (OzoneLife, São José Dos Campos, São Paulo, Brazil).

For ozone pretreatment, samples with $65 \mathrm{~g}$ of green apple cubes were exposed to different processing times: 10, 20 or 30 minutes. The oxygen flow was $250 \mathrm{~mL} / \mathrm{min}$ and the ozone production was $40.9 \mathrm{mg} / \mathrm{L}$.

For drying, $55 \mathrm{~g}$ of ozone pretreated green apple cubes were dried in a fluidized bed dryer (Labmaq do Brasil, Ribeirão Preto, São Paulo, Brazil). The ozone pretreated apples were dried at $50{ }^{\circ} \mathrm{C}$ because this temperature resulted in the highest diffusivity of drying.

\subsection{Quality parameters of the dried apples}

The sample's moisture was determined using a moisture balance (Marconi, PiracicabaBrazil). The water activity was determined at $25^{\circ} \mathrm{C}$ with a water activity meter (AquaLab, Decagon CX-2, Pullman, Washington, USA). The drying kinetics the thermal diffusivity apples were calculated according to the Fick's law.

The instrumental color was determined using a Minolta CR300 colorimeter (Tokyo, Japan) and the color parameters were expressed as L* (whiteness/darkness), a* (redness/greenness), $\mathrm{b}^{*}$ (yellowness/blueness), $\mathrm{C}^{*}$ (saturation index) and ${ }^{\circ} \mathrm{h}$ (hue angle). The readings were done in quintuplicate and the total color difference $(\Delta \mathrm{E})$, was calculated according to the following equation:

$$
\Delta E=\sqrt{(\Delta L)^{2}+(\Delta a)^{2}+(\Delta b)^{2}}
$$

Total phenolic compounds were determined by the Folin-Ciocaulteu method ${ }^{2}$. 


\section{Results and Discussion}

\subsection{Effects of fluidized bed drying on bioactive compounds and drying kinetics}

According to the results presented in Table 2, fluidized bed drying has influenced the activity of the spoiling enzymes reaching almost $80 \%$ of inactivation for PPO and POD at $50^{\circ} \mathrm{C}$ after 2 hours of drying. Yemenicioglu et al. $(1997)^{6}$ reported that the time required for $50 \%$ reduction of initial PPO activity of Granny Smith apples at $68^{\circ} \mathrm{C}$ and $78^{\circ} \mathrm{C}$ was 35 and 3 min, respectively, showing the effect of temperature on PPO. Antioxidant capacity (DPPH) also decreased due to the drying processes. However, at $40^{\circ} \mathrm{C}$ it was observed an increase of $200 \%$ for total phenolic compounds (TPC), which agrees to the highest antioxidant value found at $40{ }^{\circ} \mathrm{C}$. Possibly, drying promoted the release of insoluble phenolics increasing both the phenolic content and the antioxidant activity. Water activity reached values below 0.4 , after $2 \mathrm{~h}\left(50^{\circ} \mathrm{C}\right), 2.4 \mathrm{~h}\left(45^{\circ} \mathrm{C}\right)$ or $3 \mathrm{~h}\left(40^{\circ} \mathrm{C}\right)$ of drying, which is appropriate to prevent bacterial and fungi growth. The results suggest that fluidized drying is a viable technology for drying apples.

Table 2. Residual concentrations of total phenolic compounds, polyphenol oxidase (PPO), peroxidase (POD) and total antioxidant activity (DPPH) of fluidized bed dried green apple

\begin{tabular}{llllll}
\hline \multirow{2}{*}{ Temp. } & \multicolumn{2}{l}{ Residual Concentrations (\%) } & & \multicolumn{1}{c}{ Diffusivity } \\
\cline { 2 - 5 } & TPC & PPO & POD & DPPH & $\left.\mathbf{( 1 0}^{\mathbf{9}} \mathbf{~ m}^{\mathbf{2}} / \mathbf{m i n}\right)$ \\
\hline $40^{\circ} \mathrm{C}$ & $301.47 \pm 22.78$ & $30.46 \pm 1.07$ & $31.61 \pm 0.89$ & $101.44 \pm 0.32$ & $8.50 \pm 1.02$ \\
$45^{\circ} \mathrm{C}$ & $88.11 \pm 2.92$ & $31.42 \pm 1.00$ & $39.53 \pm 1.51$ & $36.82 \pm 2.78$ & $11.50 \pm 0.85$ \\
$50^{\circ} \mathrm{C}$ & $78.25 \pm 1.14$ & $21.36 \pm 2.54$ & $15.30 \pm 0.43$ & $27.82 \pm 0.79$ & $16.50 \pm 3.20$ \\
\hline
\end{tabular}

\subsection{Ozone pretreatment}

The ozone pretreatment reduced the water diffusivity as showed in Table 3, which leads to a reduced drying efficiency. The negative effect on the water diffusivity was proportional to the ozone application time. After 30 min of ozone pretreatment, the diffusivity was reduced by $43 \%$. This might be occurred probably due to structural changes after increasing time exposure to ozone.

Table 3. Diffusivity values of ozone pretreated apples at $50^{\circ} \mathrm{C}$

\begin{tabular}{cc}
\hline Time (min) & $\begin{array}{c}\text { Diffusivity } \\
\left(\mathbf{1 0}^{\mathbf{9}} \mathbf{~}^{\mathbf{2}} / \mathbf{m i n}\right)\end{array}$ \\
\hline 0 & $16.50 \pm 3.20$ \\
10 & 15.80 \\
20 & 12.90 \\
30 & 9.39 \\
\hline
\end{tabular}


The results of the color analysis are presented in Table 4 . The color difference $(\Delta \mathrm{E})$ was calculated against the control sample (non-dried apple). For all pretreated samples, the drying process increased the total color difference, but this variation was lower when the drying was combined with the ozone pretreatment. Thus, it is possible to state that the application of ozone before drying reduced the color changes during drying. The mechanism involved are object of future studies.

Table 4. Colors values of fluidized bed dried green apple

\begin{tabular}{lcccccc}
\hline & $\mathbf{L}^{*}$ & $\mathbf{C}^{*}$ & $\boldsymbol{h}$ & $\mathbf{a}^{*}$ & $\mathbf{b}^{*}$ & $\boldsymbol{\Delta} \mathbf{E}$ \\
\hline Control-OZ 10 & 76.03 & 24.51 & 99.42 & -4.01 & 24.18 & - \\
OZ 10 & 68.53 & 9.74 & 100.65 & -1.80 & 9.57 & 16.56 \\
OZ 10 + FB & 62.19 & 14.80 & 91.63 & -0.47 & 14.80 & 17.09 \\
\hline Control-OZ 20 & 72.34 & 24.21 & 114.97 & -10.22 & 21.95 & - \\
OZ 20 & 69.17 & 13.39 & 100.58 & -2.46 & 13.16 & 12.14 \\
OZ 20 + FB & 63.08 & 15.09 & 92.43 & -0.64 & 15.08 & 14.99 \\
\hline Control-OZ 30 & 72.02 & 14.21 & 101.07 & -2.73 & 13.94 & - \\
OZ 30 & 63.30 & 22.15 & 87.28 & 1.05 & 22.12 & 11.06 \\
OZ 30 + FB & 76.03 & 24.51 & 99.42 & -4.01 & 24.18 & 13.85 \\
\hline Control & 86.53 & 22.05 & 107.80 & -6.73 & 20.99 & - \\
FB 50 ${ }^{\circ} \mathrm{C}$ & 68.73 & 17.09 & 76.08 & 4.11 & 16.59 & 21.3 \\
\hline
\end{tabular}

Control: non-processed apple; $\mathrm{OZ}$ - sample submitted to ozone treatment; $\mathrm{OZ}+\mathrm{FB}$ - sample submitted to ozone treatment followed by fluidized bed drying.

Table 5 shows the residual activity of PPO and POD after ozone pretreatment and fluidized bed drying.

Table 5. Residual activities (\%) of ozone pre-treated and fluidized bed dried green apple

\begin{tabular}{lcc}
\hline & POD & PPO \\
\hline OZ 10 & $442.96 \pm 5.90$ & $162.28 \pm 13.94$ \\
OZ 10 + FB & $243.80 \pm 13.22$ & $30.54 \pm 13.25$ \\
\hline OZ 20 & $85.71 \pm 2.96$ & $102.42 \pm 4.84$ \\
OZ 20 + FB & $182.56 \pm 8.84$ & $48.68 \pm 8.50$ \\
\hline OZ 30 & $76.24 \pm 0.0$ & $121.10 \pm 3.06$ \\
OZ 30 + FB & $54.92 \pm 3.06$ & $49.55 \pm 6.04$ \\
\hline
\end{tabular}

The maximum reduction (23.76\%) was achieved after 30 minutes of ozone exposure. An inhibitory effect of ozone on POD occurred probably due to the high oxidation potential of ozone $^{7}$. For PPO the activity increased up to $62 \%$ after short time ozone processing (10 min) and then it was reduced. After drying, PPO activity decreased probably due to the temperature effect (Table 2). The highest enzymes inactivation was achieved in the samples treated with ozone by 30 minutes. However, the POD and PPO residual activity were higher than the found in the samples dried without the ozone pretreatment. 


\section{Conclusions}

Our results suggest that fluidized bed drying is a viable technology for drying apples. The ozone pretreatment resulted in unexpected results since the pretreatment reduced the water difusivity and promoted an increase in the enzyme activity. The treatment time strongly afftected the final PPO and POD activity. On the other hand, the ozone treatment resulted in lower color changes when compared to non-ozone treated dried apples.

To our knowledge this the first study applying ozone as pretreatment for fruit drying. The results strongly suggest a behavior similar to the ultrasound pre-treatment where some parameters can increase or decrease depending on the intensity and processing time. Thus, more studies on the effect of ozone as pretreatment for drying fruits are necessary to understand the mechanism of the effects reported in the present study.

\section{References}

[1] Zhang, M.; Chen, H.; Mujumdar, A. S.; Tang, J.; Miao, S.; Wang, Y. Recent Developments in High-Quality Drying of Vegetables, Fruits, and Aquatic Products. Crit. Rev. Food Sci. Nutr. 2017, 57 (6), 1239-1255.

[2] Fonteles, T. V.; Costa, M. G. M.; de Jesus, A. L. T.; de Miranda, M. R. A.; Fernandes, F. A. N.; Rodrigues, S. Power Ultrasound Processing of Cantaloupe Melon Juice: Effects on Quality Parameters. Food Res. Int. 2012, 48 (1), 41-48.

[3] Sharada, S. Studies on Effect of Various Operating Parameters \& Foaming AgentsDrying of Fruits and Vegetables. Int. J. Mod. Eng. Res. 2013, 3 (3), 1512-1519.

[4] Sivakumar, R.; Saravanan, R.; Elaya Perumal, A.; Iniyan, S. Fluidized Bed Drying of Some Agro Products - A Review. Renew. Sustain. Energy Rev. 2016, 61, 280301.

[5] Chen, J.; Hu, Y.; Wang, J.; Hu, H.; Cui, H. Combined Effect of Ozone Treatment and Modified Atmosphere Packaging on Antioxidant Defense System of Fresh-Cut Green Peppers. J. Food Process. Preserv. 2016, 40 (5), 1145-1150.

[6] Yemenicioğlu, A.; Özkan, M.; Cemeroğlu, B. Heat Inactivation Kinetics of Apple Polyphenoloxidase and Activation of Its Latent Form. J. Food Sci. 1997, 62 (3), 508510.

[7] Miller, F. A.; Silva, C. L. M.; Brandão, T. R. S. A Review on Ozone-Based Treatments for Fruit and Vegetables Preservation. Food Eng. Rev. 2013, 5 (2), 77106. 